\title{
HACÍA UNA NORMATIVA PARA LA PROTECCIÓN DEL MEDIO AMBIENTE PRINCIPIADA POR EL IDEALISMO TRASCENDENTAL DE IMMANUEL KANT.
}

\section{TOWARD NORMS FOR ENVIRONMENTAL PROTECTION PRINCIPLED BY IMMANUEL KANT'S TRANSCENDENTAL IDEALISM.}

\author{
Leonardo Rivera Mendoza ${ }^{1}$ \\ Asesoría de investigación: Bessy M. Nazar²
}

\section{RESUMEN.}

Esta es una propuesta de inclusión de los deberes ambientales en la Doctrina de la Virtud y la Doctrina del Derecho de La metafísica de la moral de Immanuel Kant. Toma la forma de una in-dagación sobre la posibilidad de recurrir al idealismo trascendental como guía para determinar deberes éticos y jurídicos ambientales y contribuir a la sistematización de una nueva deóntica ambiental. Desde el principio general del imperativo categórico, se deducen aquí cuatro principios especiales de ética ambiental y tres principios especiales del derecho ambiental, con la intención de proponer-los como criterio direccionador de nuevas normas referentes al medio ambiente.

PALABRAS CLAVE: medio ambiente, idealismo trascendental, ética, derecho, moral.

\section{ABSTRACT.}

This is a proposal for the inclusion of environmental duties in the Doctrine of Virtue and the Doctrine of Right of Immanuel Kant's The Metaphysics of Morals. It takes the form of an inquiry on the possibility of appealing to transcendental idealism as a guide to determining ethical and juridical environmental duties and to contribute to the systematization of a new environmental deontic. From the general principle of the categorical imperative, four special principles of environmental ethics and three special principles of environmental right are drawn, hereby to be brought forward as guiding criterion for new norms referring to the environment.

KEYWORDS: environment, transcendental idealism, ethics, right, morals.

Recibido: 31 Agosto 2018

Apobado: 11 de octibre 2018

1 Estudios de Licenciatura en Derecho, Facultad de Ciencias Jurídicas, Universidad Nacional Autónoma de Honduras. Operador de justicia en materia civil, Poder Judicial de Honduras. E-mail: riveramd.leonardo@gmail.com

2 Decana de la Facultad de Ciencias Jurídicas de la Universidad Nacional Autónoma de Honduras. Profesora titular II del departamento de Derecho Administrativo. Licenciatura en Ciencias Jurídicas y Sociales con orientación en Dere-cho Administrativo; Máster en Administración de Empresas; Especialista en Diseño, Gestión y Evaluación Curricular; Máster en Derecho Constitucional en la Universidad de Valencia, España.E-mail: bessy.nazar@unah.edu.hn. 


\section{METODOLOGÍA.}

El presente trabajo se vale de un recurso a la metodología filosófico-metafísica del idealis-mo trascendental de Immanuel Kant, elucidado mediante exégesis interpretativa, para hacer una exploración de su aplicabilidad a la deóntica ambiental. El método empleado es un ejercicio sintéti-co desde el principio práctico del imperativo categórico hacia los principios especiales ambientales que expongo como resultado.

\section{Preámbulo.}

Está siendo gradualmente superada la noción de que las condiciones ambientales son in-munes a fluctuar a causa de la actividad humana. Se ha encontrado que la estabilidad en las condi-ciones atmosféricas depende de un delicado balance susceptible de ser lesionado por la operación de nuestra especie, con especial acento desde la revolución industrial (Mgbemene, Nnaji y Nwozor, 2016).

A la vez, hemos sido testigos de un período de extinción masiva de especies que ha conti-nuado desde el Pleistoceno (Zalasiewicz et al., 2008), claramente influenciado por nuestro impulso por la adquisición, el consumo y la expansión. Hemos explotado los recursos naturales disponibles a tal grado que estimados proponen que para el año 2050 la producción agrícola deberá haber incrementado en un $70 \%$ para evitar una crisis alimentaria inclusive más grave que la actual (Bruinsma, 2009) —aúnese a ello la destrucción de innumerables ecosistemas para transformarlos en tierra arable - ante una tendencia constante al incremento poblacional, especialmente en naciones pobres (Walker, 2016).

Parece ser tarde que nos enteramos, finalmente, del potencial nocivo de nuestra influencia en el planeta y todo esto sugiere que las próximas décadas serán significativamente problemáticas para el sostenimiento de la vida en la Tierra, sea de nuestra especie o de cualquiera otra.
Pero encontramos ahora loables esfuerzos por mitigar - y revertir, en la medida de lo posibleel daño que hemos causado a nuestro alrededor. Existen múltiples y ambiciosos compromisos internacionales, campañas de concientización y de difusión de datos científicos, así como de sensibilización acerca de la necesidad de un medio ambiente sano para el goce efectivo de los derechos humanos $^{3}$. Sin embargo, es posible ver a esta realidad desde un enfoque más escéptico. Bien puede ser que nuestros esfuerzos actuales por proteger al medio ambiente sean insuficientes, que la vida en nuestro planeta enfrente una condena firme al sufrimiento en los próximos años, y que al-guien se pregunte: "¿por qué he de sacrificarme ahora (o sacrificar mis intereses) si pronto todos estaremos proclives a perecer aflictivamente?" o bien "a falta de culpa de mi parte, ¿por qué debo cambiar mis condiciones de vida por un futuro incierto si, mientras tanto, puedo no hacerlo?». En el presente trabajo elaboro una posible salida a la tensión entre la posición proactiva y la escéptica, a través de comentarios sobre posibles normas ambientales, derivados de la filosofía práctica kantiana.

\section{El finalismo ambiental y la necesidad de un principio general para las normas respecto al ambiente.}

La nueva emergencia por la protección de la sostenibilidad en las condiciones del planeta ha ocasionado que se recurra a dar una nueva dimensión a la deontología, ahora relativa al medio am-biente. Esta pretende examinar las decisiones que tomamos con referencia a las cosas que confor-man los ecosistemas del planeta, y propone regular nuestra conducta mediante normas -éticas y jurídicas - cuya característica en común es el convencimiento de que dar continuidad al arraigo de máximas y conductas lesivas para el medio ambiente es un prospecto de alta problematicidad moral; y en que es necesario hacer una revisión de nuestro

3 Encuentro posible concluir no solo que se vincula, sino que esta protección debe ser vista como de la protección de los derechos a la vida, a la integridad personal y a la libertad personal de cada agente humano. 
vínculo con el entorno, la forma en que conducimos nuestra economía, y nuestro convencimiento sobre el supuesto interés de la humanidad por sobre el bienestar de las demás entidades en el mundo.

Desde ello, y en un tiempo relativamente corto, se ha llegado al convencimiento de que la comprensión y terapia de las dinámicas de los ecosistemas terrestres son temas relevantes para toda la actividad humana, que admiten una pluralidad de criterios que abonen a diseñar mejores principios y prácticas de explotación, valoración y uso de los recursos naturales a nuestra disposición.

Bien cuando no es posible negar que la convergencia de disciplinas y actores interesados por la protección del ambiente provea de un aporte benéfico y científicamente valioso para el estu-dio de las mejores maneras de conservación del planeta, también es posible reconocer que la presencia de una variedad de enfoques no asegura inmunidad frente a ciertas dificultades para establecer reglas universales de conducta ante el medio ambiente, que sean concretas y de observancia general. Por el contrario, puede ser que la multitud de perspectivas implicadas origine una insoste-nible diversidad de propuestas sobre prácticas ambientales normativamente compulsorias (acerca de qué hacer para la protección del ambiente, qué esperar y por qué hacerlo) ${ }^{4}$.

Es así que, a pesar del claro interés por la protección del medio ambiente, parece que la nueva deóntica ambiental no ha llenado aun, con suficiente seguridad, el espacio de un elemento

4 Podemos ejemplificarlo con un escenario. Cierto agente sostiene que la superpoblación humana es un problema que debe ser solucionado de inmediato si se desea que nuestro planeta sea habitable a futuro, y propone un pro-grama de esterilización forzada en [...] lugar. Otro dice que el programa de esterilización no debe ser implementado con el objetivo de que el planeta sea habitable, sino con el objetivo de asegurar una mejor distribución de recursos y acceso equitativo a servicios en el presente. Otro propone que los programas de esterilización forzada son antiéti-cos. Otro propone que estos programas son antijurídicos. Otro sostiene que la superpoblación no es un problema en lo absoluto. ¿Quién está legitimado para proponer normas generales de conducta? indispensable para dotar de una direccionalidad clara a su desarrollo: un principio general único. Puede ser del máximo interés para filósofos y juristas, entonces, contar con una herramienta de razonamiento práctico que legitime el cómo y el por qué es recomendable que las personas incorpo-ren una consideración por el medio ambiente en sus máximas éticas; o cómo y por qué es deber de la autoridad política legislar normas ambientales, optimizándolas lo más posible; o cómo y por qué es deber de la ciudadanía cumplir estas leyes civiles con objeto en el medio ambiente, indistinta-mente de sus intereses más inmediatos.

En este trabajo, propongo que tomemos como tal principio al imperativo categórico kantiano. Concretamente, lo utilizamos para hacer una respuesta a una tendencia normativista que llamaremos "finalismo ambiental». Según esta, cada actor — desde su propia intencionalidad - se plantea una situación problemática y fija objetivos deseables para solucionarla, pretendiendo que sean compartidos por cualquier otro agente (apelación a la universalidad). Existe un radical proble-ma con el finalismo, sin embargo, en que aun cuando estos objetivos posiblemente son válidos, se encuentran determinados por una subjetividad empírica: la doctrina científica o la epistemología moral favorecida por el actor; por ello, basta con desentenderse del enfoque escolástico de cada ciencia para no suscribirse a los deberes ambientales que esta pretenda justificar. Tal subjetividad es naturalmente carente de validez universal (al yacer sobre proposiciones a posteriori) y, por tanto, no es indubitablemente idónea para generar preceptos conductuales de rigurosa validez ${ }^{5}$.

5 Para el caso, el Acuerdo de París, artículo 2.1.a) se propone inhibir el progreso del cambio climático para que la temperatura media de la superficie del planeta no llegue a los dos grados centígrados sobre niveles preindustriales. Pero hay agentes que se han convencido de que el cambio climático no es un hecho comprobado. Es posible que, a pesar de su convicción, estos agentes mismos contribuyan a mitigar el alza en temperaturas al actuar desde máximas que no se dirijan hacia este objetivo en específico, sino que surjan desde una noción apriorística del deber ambiental mismo. 
Recurrimos, entonces, a la filosofía moral kantiana como solución para la consecuente heterogeneidad en la motivación, objeto y fines de las normas ambientales, pues en ella se busca identificar reglas válidas a priori, para todo agente racional concebible, por medio de la crítica de las facultades de la mente humana. Si bien Kant no llega a formular deberes estrictamente ambientales en sus trabajos, un ejercicio en razonamiento ético que haga uso de las herramientas provistas en La metafísica de la moral $^{6}$ muestra una interesante oportunidad para incluir en ella un nuevo conglomerado de deberes cuyo objeto sean las entidades y dinámicas que conforman el medio ambiente. Este enfoque cuenta, además, con el llamativo de encontrar normas ambientales coherentes con el resto del sistema de idealismo trascendental, ligando a la ética y al derecho en la filosofía moral, y a la vez con el resto de la cognición científica (sistemática) por medio de la razón práctica?

\section{El idealismo trascendental, la mente humana y la teleología natural.}

Previo a entrar en la elucidación de deberes ambientales que hemos anticipado (nivel práctico), es importante tener una idea de la crítica epistemológica del idealismo trascendental (nivel especulativo), que propone una perspectiva especial acerca de la relación entre los objetos no racionales del mundo y el ser humano, como sujeto cognoscente de ellos. Esto es relevante para resaltar la diferencia entre nuestra propuesta y la del finalismo frente al problema de la posibilidad de postular apodícticamente el fin de las cosas que se presentan en nuestra experiencia con respecto a nosotros mismos.

6 Kant (1968). Por motivos de estándar, todas las referencias a los trabajos de Kant en este documento remiten a su reproducción en la Akademieausgabe, salvo las de la Crítica de la razón pura (para la que usamos la primera y la segunda edición original). Toda cita de estas obras en español es traducción del autor de este ensayo.

7 Es importante tener presente que esta ligadura es sui generis y, en mi opinión, no susceptible de un cuestionamien-to estándar a la vinculación entre el derecho y la moral, como el avanzado por el positivismo jurídico tradicional que, bajo un figurae dictionis, confunde a la ética con la moral.
La respuesta tradicional al problema es dogmática, realista y utilitarista. Dirá que el fin de las cosas no humanas es el de atender a nuestras necesidades, estar a nuestro servicio y abonar a nuestra autorrealización ${ }^{8}$. Reprochablemente, el que este postulado haya adquirido carácter nómico es precisamente uno de los motivos por los que se han legitimado las operaciones progresivas y graduales de corrupción antropogénica de las condiciones del ambiente, por constituirse en un discurso justificante del abuso de nuestro entorno, bajo el argumento de que "ha sido útil (o bueno) para la humanidad ${ }^{9}$. El finalismo ha propiciado, así, un amplio margen de arbitrariedad en el uso de los recursos naturales que se justifica en (a) la noción realista de que conocemos las cosas, las relaciones entre ellas y sus fines como son y (b) el dogma teleológico-eudemónico de que el fin de estas cosas es el bienestar humano.

La segunda proposición cae junto con la primera ante el idealismo trascendental, pues este justamente niega que los humanos seamos capaces de intuiciones de las cosas como son en sí (intuiciones intelectuales) ${ }^{10}$. Tal negación, a nivel teórico, limita la supuesta realidad objetiva en nues-tra representación de los objetos - y cualquier juicio acerca de sus fines - eliminando toda pretensión de verdad en el utilitarismo y en el dogma del servilismo antropocéntrico ${ }^{11}$.

8 Esto se traza, por ejemplo, hasta el fundamento de las religiones abrahámicas. Cf. Génesis 1:28-31.

9 Para la distinción kantiana entre lo subjetivamente bueno y lo objetivamente bueno, cf. Kant (1963c, p. 207-209). El utilitarismo de este argumento únicamente se subsumiría bajo lo subjetivamente bueno, y corresponde a imperativos técnicos, no al categórico.

10 Sino solamente capaces de representaciones ubicadas en el tiempo y en el espacio producidas por la afectación de los objetos sobre la sensibilidad humana. La idealidad de las formas de la sensibilidad es una de las marcas distinti-vas del idealismo trascendental (Kant, 1781, p. 127, 225, 369, 490-491, 493-94; 1787, p. 272, 518-519, 522-23).

11 Tómese, por ejemplo, la caza de megafauna por motivos deportivos o por la asignación arbitraria de un valor comercial a partes de sus cuerpos. Solo una degeneración del antropocentrismo utilitario puede llevar a la contraproducente continuidad de prácticas que conducen a la extinción de estos objetos del [problemático] interés de algunos agentes humanos. 
A pesar de que Kant justifica el principio de que la naturaleza debe ser vista como teniendo un propósito -en atención a la sistematicidad en que deriva la adjudicación de los objetos al entendimiento humano ${ }^{12}$ - también niega que sea uno que se pueda conocer de las cosas en sí, sino solo posible de ser asumido subjetivamente en el juicio reflectivo ${ }^{13}$. En consecuencia, también cuestiona la sostenibilidad de la aseveración de que el propósito de la naturaleza en dotar al ser humano de razón sea el de proveernos con un medio para la satisfacción de nuestros intereses, cuya suma es llamada "felicidad" ${ }^{14}$. Por el contrario, al plantearse esta pregunta en los Cimientos para la metafísica de la moral (Kant, 1963a, p. 395), responde que si la felicidad humana fuera el propósito de la naturaleza, no sería idónea para lograrlo el implantar razón en los individuos, sino implantarles el mero instinto ${ }^{15}$. Kant sostiene que la razón humana - como la facultad de identificar principios ${ }^{16}$ - se dirige, hacia (a) el ascenso en condicionantes en su uso teórico ${ }^{17}$, y (b) la determinación de la voluntad, de acuerdo con la forma de una ley moral, en su uso práctico ${ }^{18}$.

Si la razón práctica solo nos ofrece la forma de una ley moral universal como fundamento de

12 De los objetos de la experiencia no se puede conocer propósito alguno, sino solo su historia fenoménica, asumién-dose que se dirigen hacia algo según la direccionalidad del juicio. Para la suscripción de Kant a la orientación teleo-lógica de la naturaleza, cf. Kant (1781, p. 799-800; 1787, p. 827-828; 1969b, p. 18-19, 27; 1963c, p. 176; 1969a, p. 27, 34 nota).

13 Pues las normas de la organización de la multiplicidad de intuiciones en un sistema en el tiempo conducen a asumir un propósito, cf. Kant (1971, p. 205, 233, 235, 239, 240, 247)

14 Kant hace esta designación en la Crítica de la razón pura (Kant, 1781, p. 806; 1787, p. 834), en los Cimientos para la metafísica de la moral (Kant, 1963a, p. 399) y en la Crítica de la razón práctica (Kant, 1963b, p. 34).

15 Cf. también Kant (1979, p. 1322, 1329; 1963b, p. 61), también especula que el propósito natural del ser humano es el cosmopolitismo en Kant (1973, p. 331).

16 Para la razón como facultad de principios, cf. Kant (1781, p. 299-300; 1787, p. 355-56; 1963b, p. 119-20; 1971, p. 201).

17 Función negativa, cf. Kant, (1781, p. 62-64, 132; 1787, p. 87$88,171)$.

18 Función positiva, cf. Kant (1781, p. 795-804; 1787, p. 823-25; 1963b, p. 20,42, 48-50, 62). los deberes humanos, entonces los principios materiales del finalismo o del eudemonismo (la bús-queda de la felicidad), junto con su pesquisa por la satisfacción de intereses concretos, quedan proscritos de ser vistos como doctrinas originantes de normas, por emanar desde $-\mathrm{y}$ contribuir a perpetuar - el concurso de subjetividades al que hemos atribuido la actual ausencia de un principio claro para la normativa ambiental. Por ello, cualquier objetivo de individuos o grupos por mejorar las condiciones del planeta, p. ej., frenar el alza en las temperaturas atmosféricas, proteger especies en extinción, reducir la emisión de gases de efecto invernadero, entre otros -o inclusive por continuar con la degradación del ambiente para satisfacer intereses individuales - no podrá contar con fuerza normativa en sí y desde sí, pues —aunque exista un beneficio previsible para algún agente - todos estos son principios empíricos no susceptibles de producir leyes prácticas válidas, y el consenso sobre ellos es meramente contingente y posiblemente frágil ${ }^{19}$.

\section{La "fórmula de la humanidad" del imperativo categórico como posible principio de la nor-mativa ambiental.}

Este freno al finalismo y al eudemonismo moral habilita a Kant con un espacio para justificar deberes a priori para los agentes humanos, que funjan simplemente como "la necesidad de una acción desde el respeto por la ley" (Kant, 1963a, p. 400; 1963b, p. 32). El valor moral de las máximas que estos asuman implica la constricción en la búsqueda de satisfacciones específicas, cuando los objetos de estas sean contrarios a la ley moral ${ }^{20}$. En cuanto al ambiente, esto limitará el espectro de acción motivada solamente por un espíritu de provecho propio (individual o colectivo), por deber siempre ceder ante las prescripciones morales puras relativas a nosotros mismos y a las de-más entidades del mundo (sean o no humanas).

19 Cf. Kant (1963b, p. 21, 26, 28, 36, 62) y el ejemplo en supra, nota 2.

20 Cf. Kant (1968, p. 216-17; 1963b, p. 20-21, 80). 
Para seres finitos, como los humanos, el principio del deber desde el respeto por la ley moral es el del imperativo categórico. La segunda de sus fórmulas -la "fórmula de la humanidad como propósito en sí misma" (Kant, 1963a, p. 429; 1963b, p. 87; 1968, p. 435) — implica que todo ser humano, visto como agente racional, tiene la libertad de asumir y perseguir sus propios fines ${ }^{21}$ y conlleva, lógicamente, la prohibición de que los seres humanos lesionen o utilicen la humanidad en sí mismos o en los demás, sin respeto a su dignidad. La fórmula de la humanidad es central en la especificación de deb eres que Kant hace en La metafísica de la moral ${ }^{22}$ y será central en nuestra deducción de deberes ambientales.

Aplicando estas consideraciones prácticas al mundo sensible, los requisitos para que un ser ejerza compulsión sobre el ser humano son (a) que este sea una persona (i.e. que sea receptivo de respeto por la ley moral ${ }^{23}$ ) y (b) que sea dado como un objeto de la experiencia (i.e. que podamos ubicarlo en tiempo y espacio ${ }^{24}$ ). Desde ello, los únicos seres en el mundo capaces de compeler a los humanos por medio de deberes morales son otros seres humanos (Kant, 1968, p. 240-41, 442). Los animales, las plantas y los objetos no animados no son agentes racionales para nosotros ${ }^{25}$, por lo que no debemos 21 En ese sentido, cf. Kant (1979, p. 1,321; 1963b, p. 87).

22 Esta importancia es enfatizada por Wood (2000, 12-13).

23 Kant, (1969a, p. 27-8). O bien, que exhiba la tenencia de actuar bajo la representación «yo» ante la experiencia humana (1973, p. 127).

24 Cf. supra, nota 8.

25 Dado que, según el Tercer Paralogismo en la Crítica de la Razón Pura (Kant, 1781, p. 361-366) la agencia racional solo es presentada en el sentido interno (como consecuencia de la espontaneidad del pensamiento) solo podemos concebir esta presentación inmediata de racionalidad en nosotros mismos como sujetos pensantes. $\mathrm{La}$ indicación de racionalidad en otros seres humanos atiende a un juicio estético habilitado por que «la expresión visible de las ideas morales, que gobiernan internamente a los seres humanos, por supuesto que solamente puede ser extraída de la experiencia» (Kant, 1963c, p. 236), juicio que exhibe una apelación a la universalidad justificada en su remisión a un «sentido común», i.e., compartido, pero por la vía estética (Kant, 1963c, p. 239, 293). Creo que la materia de este sentido común manifestado en el mundo, si fuera posible, sería relativa a la predisposición neurobiológica humana a la comunicación y el lenguaje. Si esto es cierto, podemos verlos como fines en sí mismos ${ }^{26}$, sino como medios para el fin que les adscriba el agente racional ${ }^{27}$. Así, todo deber humano entrará bajo los deberes de cada uno para consigo mismo, o bajo los deberes de cada uno para con los demás seres humanos. El objeto - pero no la fuente de la determinación ${ }^{28}$ de los deberes para con uno mismo será a el perfeccionamiento propio, que puede ser natural o moral $^{29}$. Los deberes para con los demás, por su parte, tendrán como objeto promover el bienestar de otros agentes racionales ${ }^{30}$.

Reconozcamos que esta taxonomía logocéntricoantropocéntrica ${ }^{31}$ puede parecer un impase para el diseño de deberes genuinamente ambientales (pues el ambiente, en todo caso, refiere a entidades no exclusivamente humanas), pero a continuación justificaremos que el idealismo trascendenta deja lugar para formular deberes ambientales suficientes y de plena obligatoriedad sobre el ser humano, sin necesidad de alterar la clasificación provista en La metafísica de la moral. Si esto se sostiene, los deberes ambientales se dividirán en (a) deberes ambientales para con uno mismo, y (b) deberes ambientales para con otros seres humanos.

tomar como coagentes racionales, además de a nosotros mismos, a aquellos seres que efectivamente nos indiquen esta agencia, vía comunicación humana basada en las formas de la intuición humana $\mathrm{y}$, entonces, solo podemos tener por agentes racionales a aquellos seres humanos que cuenten con el uso de sus facultades cognitivas para actuar de acuerdo con máximas y exhibir esta agencia ante el observador. Se notará que esto no censura la posibilidad real de la existencia de otros entes racionales en este planeta o en algún otro, pero limita nuestro juicio acerca de tal racionalidad en tanto el ser racional no se presente como ser humano.

26 Por no presentar la aptitud de actuar de acuerdo con la representación de leyes, sino solo conforme a inclinaciones patológicas (Kant, 1963a, p. 412).

27 Cf. Kant (1963a, p. 428; 1979, p. 1,329). Resulta obvio, entonces, que la filosofía kantiana no es homóloga de las posturas éticoambientalistas de valor absoluto de las entidades no humanas.

28 «Ursprung». Recuérdese que la fuente de la determinación de deberes es únicamente la ley moral, cf. Kant, (1963b, 78-79).

29 Kant, (1968, p. 444-47). Kant ve al ser humano como un ser animal y como un ser moral; estos niveles de perfeccionamiento corresponden a ambas perspectivas.

30 Kant, (1968, p. 387-88; 1969a, p. 3-4 nota). La contribución que hacemos a la felicidad de otros es denominada «equidad» (1979, p. 1,330$)$.

31 Tomo el término «logocentrismo» de Wood (1998, p. 189). 


\section{La dimensión ética de los deberes ambientales.}

\subsection{Clasificación.}

Bajo el entendido anterior, y si los deberes ambientales son aptos para ingresar a la Doctri-na de la Virtud de La metafísica de la moral, mostrarán las siguientes marcas: (a) serán imperfectos, pues orientan la producción de máximas que apliquen para una relativa generalidad de situaciones (Kant, 1968 , p. 240); y (b) serán simultáneamente directos e indirectos, dependiendo del objeto con el cual se confronten. Pueden verse como directos cuando tengan relación con un agente racional que ejerce compulsión frente a nuestra libertad. Podrán ser vistos como indirectos los que tengan relación con un objeto no racional (Kant, 1968, p. 442). El que un deber sea visto como directo o indirecto, en consecuencia, no aduce a su fuerza obligacional, sino únicamente a la perspectiva desde la que se lo examine, y la utilidad de esta diferencia radica en su potencial ponderativo en la deducción de deberes concretos ${ }^{32}$. Entendido esto, dedicaremos

32 P. ej. tenemos un deber directo para con nosotros mismos de no causar sufrimientos innecesarios a los animales, el cual es a la vez un deber indirecto con respecto a los animales mismos. Me separo de Wood (1998, p. 202) en este punto, pues, según su lectura, el «principio de personificación» que atribuye a Kant tiene como consecuencia la generación de deberes directos de cara a las entidades «racionales no humanas» en el mundo, i.e., las indicacio-nes de naturaleza racional potencial, parcial o residual en las criaturas que no indiquen un libre arbitrio (inclusive los seres humanos muertos, en estado embrionario temprano o con daño neurológico severo). Wood dice que la intro-ducción de los deberes indirectos se debe a «constricciones teóricas» que afectaron a Kant, pero parece obviar la posibilidad de que un mismo deber pueda ser visto como directo o indirecto a la vez, dependiendo del objeto con el que se los confronte. Por lo tanto, el logocentrismo que menciono debe ser visto como una perspectiva de subjetividad antropológica cuya consecuencia es un antropocentrismo meramente epistémico. En respuesta a la negativa, que dice compartir con Guyer, sobre un "procedimiento mecánico» para decidir entre la compulsión desde entes no racionales y los fines humanos (o de otros agentes racionales) sobre nosotros (ibid., nota 18), diré que el mero conflicto es espurio, pues un conflicto entre deber directo e indirecto es solo producto de un error en la determina-ción del deber directo. La división entre deberes qua directos o qua indirectos puede ser instrumental en asistir al agente lo sucesivo de esta sección a ilus-trar algunas "meta-máximas", derivadas de esta clasificación, que tomen la forma de principios especiales de ética ambiental.

\subsection{Primer principio especial de ética ambiental. Los deberes ambientales del ser humano para consigo mismo: su relación indirecta con los objetos no racionales.}

Los deberes ambientales para con uno mismo tienen una relación íntima con el deber de incrementar la perfección propia (Kant, 1968, p. 392393), y máximas contrarias a estos deberes obstruyen que el agente se aproxime a tal perfección. Kant hace explícito el vínculo entre las entidades no racionales y los deberes de la humanidad para consigo misma en la sección episódica de la «Anfíbola en conceptos morales de la reflexión, tomando al deber humano para consigo mismo como un deber para con otros seres" (Kant, 1968, p. 44244). Los comentarios de Kant sobre este tema serán, por sí mismos, útiles para deducir un principio especial. Ahora los resumimos.

(a) Que la propensión para destruir despliegues de belleza en la naturaleza inanimada, co-mo formaciones de cristales y plantas $^{33}$, aminora el sentimiento de amar algo sin importar el uso previsible. (b) Que el trato violento y cruel de la naturaleza animada (animales), la experimentación con ella y su sometimiento a trabajos excesivos es aún más grave, puesto que merma nuestra em-patía humana con su sufrimiento, y nuestra posibilidad de empatizar con el sufrimiento de otras personas ${ }^{34}$. (c) Y que estos deberes, inclusive el de gratitud hacia estas criaturas, "pertenecen indirectamente al deber de los seres humanos con relación a estos animales; pero, considerado como un deber directo,

para tomar decisiones basadas en la compulsión más inmediata del deber directo en caso de tener que optar por un curso u otro. 33 No veo motivo para tener por inanimadas a las plantas.

34 También en Kant, (1969d, p. 293). Kant habla de una restricción de mutilar o matar [entendemos que aflictiva e innecesariamente] a los animales domésticos. 
es siempre solo un deber del ser humano para consigo mismo" (Kant, 1968, p. 444). Es posible aunar las menciones de la belleza y la empatía con los comentarios de Kant en la Crítica de la facultad de juicio. En ella, dirá que tomar un interés inmediato por la belleza de la natu-raleza es "siempre un signo de una buena alma" y que, de ser habitual, "indica una disposición de la mente que es favorable para el sentimiento moral» (Kant, 1963c, p. 298-99) ${ }^{35}$.

Identificaremos a esta "buena alma" con una que posea una buena voluntad, y esto con la buena "forma de pensar" o Denkungsart que Kant introduce en la Crítica de la razón pura (Kant, 1787 , p. 551; 1787, p. 579) ${ }^{36}$ y que —cuando es reflexiva - es una condición subyacente necesaria, pero no suficiente, para que las máximas adoptadas por alguien tengan contenido moral ${ }^{37}$. La empatía especial para con las otras especies animales puede verse como una extensión de la apreciación de la belleza en ellos (graduada según se aproxime a la belleza humana como ideal), y de la afectación que esta belleza puede causar en nuestra facultad de juicio ${ }^{38}$.

Si esto es correcto, tanto la apreciación por la belleza de los objetos que componen el resto del 35 Cf. Kant (1963c, p. 268): «Lo bello nos prepara para amar algo, aun a la naturaleza, sin interés».

36 También cf. Kant, (1969a, p. 47-8; 1973, p. 285).

37 Allison identifica la buena voluntad con la buena Denkungsart y señala que esta es sine qua non para que las má-ximas tengan contenido moral. También dice que esta debe ser reflexiva. Cf. Allison (2011, p. 100-101).

38 Puede decirse que el juicio estético puro sobre la belleza de los animales no humanos es similar al juicio estético puro sobre la presencia de racionalidad en un ser humano, pues se basa en la presentación de cualidades cogniti-vas que conducen al observador a juzgar que la criatura es capaz de asumir fines de acuerdo con el principio de la finalidad [Zweckmäßigkeit] de la naturaleza. Es importante tener en cuenta, sin embargo, que este juicio estético solo tendrá implicaciones morales (generando deberes directos) cuando la agencia racional sea plenamente evi-denciada y ya no se juzguen los atributos cognitivos, sino la libertad del agente racional manifestada en sus actos (el juicio estético es puro cuando se juzga racionalidad, es impuro cuando se juzga moralidad). Es por ello que Kant caracteriza al ser humano como «el ideal de la belleza», mencionando a la vez que el juicio sobre la belleza huma-na es un juicio estético impuro (por implicar juicio moral). ambiente como la consideración especial por el bienestar de animales y plantas serán indicado-res de que el agente es capaz de obrar moralmente. No es, entonces, que un ataque o falta de cui-dado por esta belleza y los sentimientos de los demás animales pueda llegar a suprimir todo contenido moral de las máximas del agente; pero una disposición que se inhiba de estas prácticas puede bien indicar que el agente cuenta con el sustrato necesario para que sus máximas tengan justo ese contenido, o predisponerlo para contar con él. Por ello, el agente tiene el deber de cultivarlas en atención a su perfeccionamiento propio.

Sobre estos deberes de la anfíbola - y contando con una idea actualmente reforzada acerca de la estricta interdependencia entre los componentes del medio ambiente- nuestra propuesta es de trato unificante. De esta manera, los comentarios de Kant sobre entidades individuales de flora, fauna y minerales se podrán aplicar a las relaciones entre ellos y los demás elementos físicos que componen ecosistemas enteros. Esto obviamente podrá variar en magnitud, pudiendo recaer desde nuestra relación con planetas o sistemas planetarios hasta con microbiomas de relevancia estética o sentiente. La excepción para estos deberes, según Kant, es que el fin por el cual tenemos un interés no sea obtenible por otros medios, es decir, que no sea absolutamente necesaria la medida tomada (Kant, 1968, p. 443). Enunciemos entonces al primer principio especial de la ética ambiental de la siguiente manera:

- Principio especial de ética ambiental (1): no dañar el medio ambiente ni causar sufrimiento innecesario a las demás criaturas del mundo en consideración al perfeccionamiento moral de uno mismo.

Será éticamente correcto, -bajo el primer principio especial, e independientemente del sentimiento de empatía que pueda sentirse por las criaturas en cuestión- el diseño de máximas tales como "cuando tenga un interés por [...], 
no haré $[\ldots]$, porque [...] objeto no racional se encuentra afectado, y causarle un daño injustificado contraría mi deber al alejarme de perfeccionar mi propia disposición moral, siendo que dañaría una manifestación de la belleza natural sin causa legítima y causaría sufrimiento innecesario a los individuos racionales y no racionales que ahí vivan».

\subsection{Segundo, tercero y cuarto principio especial de ética ambiental. Los deberes ambientales para con los demás: sus cuerpos y sus fines.}

Ahora, habiéndose dicho que la consideración de la felicidad no puede ser la fuente de de-ber alguno, es posible recalcar, sin embargo, que esto no exime de que sea el objeto sobre el que recaigan algunos deberes (Kant, 1963b, p. 37, 93) ${ }^{39}$. Tomando a otros seres humanos como "seres morales" y "seres animales", y asumiendo que la constricción de nuestras inclinaciones internas puede efectivamente recaer sobre la felicidad de los demás, veremos a los otros seres humanos según (a) su cuerpo, en relación de interdependencia con su entorno y (b) sus fines, pues son agentes racionales (es decir, fines en sí mismos) que ameritan respeto por la obtención de su felicidad en la forma en que no obstruyan la ajena.

El cuerpo de cada persona es la marca primordial de la perspectiva del ser humano como ser animal, pues sin él no puede lograr ninguno de los fines que se proponga. La no lesión del cuer-po ajeno, por lo tanto, es necesaria para que exista cumplimiento de nuestro deber de no obstruir la felicidad de los

39 El que la felicidad ajena pueda ser el objeto de los deberes para con los demás se deriva de que esta es vista como la satisfacción de los intereses asumidos por cada persona. Los deberes relativos a la felicidad derivan de la Fór-mula de la Humanidad, en el sentido de que ningún ser humano se encuentra legitimado para lesionar la libertad ajena (i.e. facultad de actuar con base en sus propios fines), por lo que nuestro deber frente a los demás recae sobre el conglomerado de estos fines bajo el título de «felicidad». No es correcto atribuir a la ética kantiana una desestimación completa de la felicidad, menos aun su proscripción (Kant, 1963b, p. 110-113). Para una lectura contraria y ampliamente difundida, cf. D’Amato y Eberle (1983, p. 772). demás. Esto significa que el espíritu de protección del ambiente se dirigirá hacia la protección de los recursos necesarios para que el resto de seres humanos en el planeta pueda conservar su cuerpo ${ }^{40}$. A su vez, este es el sustrato necesario para que toda persona pueda perseguir la realización de sus fines en cualquier forma que desee ${ }^{41}$, bajo la idea de la autonomía ética, a nivel intelectual. También implica debemos velar por la promoción de las condiciones para que los demás agentes obtengan su felicidad, o bien, que tenemos un deber de cultivar prácticas que propicien la disponibilidad de recursos para que los demás seres humanos, individual o colectivamente, puedan darles un uso racional ${ }^{42}$. El respeto a ambos caracteres de los demás seres humanos es el respeto a su dignidad.

En consecuencia, los dos principios especiales siguientes serán los relativos a las dos ópticas desde las que podemos ver a los demás agentes racionales:

- Principio especial de ética ambiental (2): no dañar el medio ambiente ni causar sufrimiento innecesario a las demás criaturas del mundo en consideración a la digni-dad de otros seres humanos, dependiente de su ser animal.

- Principio especial de ética ambiental (3): no dañar el medio ambiente ni causar sufrimiento innecesario a las demás criaturas del mundo en consideración a la digni-dad de otros seres humanos, manifestada a través de su ser intelectual.

$40 \mathrm{O}$, en palabras de Kant, «preservarse a sí mismo en su naturaleza animal» (Kant, 1968, p. 421). Esto se relacio-nará, en la justificación jurídica, con el derecho a la salud, a la alimentación y a la vida digna (Naciones Unidas, Doc. E/CN.4/Sub.2/1992/16, Realización de los Derechos Económicos, Sociales y Culturales, Informe definitivo presenta-do por el Sr. Danilo Türk, Relator Especial, párrs. 118122.

41 Indistintamente de la moralidad de estos. Cf. Kant, (1969d, p. 290).

42 Frente a los grupos humanos el deber será indirecto, $c f$. infra., nota 46 . 
Máximas éticas orientadas por estas consideraciones tomarán una forma, p. ej. de «en caso de tener un interés por [...], no haré [...], porque estas afectan los recursos de los cuales dependen la animalidad (cuerpo) y humanidad (fines) de las personas en cierta área, y ello contrariaría mi deber, al obstaculizar a otros seres humanos en la obtención de su felicidad".

Ahora, la asimilación y puesta en práctica de los tres principios especiales anteriores puede configurar una práctica digna de estima que constituya virtud (Kant, 1968, p. 394 y 405; 1963b, p. 33; 1969a, p. 47). Llamaremos virtud ambiental a la fortaleza de las máximas de un ser para cumplir con los deberes cuyo objeto sea el ambiente.

Identificar la virtud ambiental es relevante ya que Kant deja una previsión numerus apertus en La metafísica de la moral, en la sección referida a los deberes para con otras personas según su condición (Kant, 1968, p. 648). Concediendo que la consignación de deberes que ha hecho no es exhaustiva, indica que es posible incluir más deberes según se examinen las características especí-ficas de agentes determinados. Me parece, entonces, que la virtud ambiental exhibida por ciertas personas puede fungir como motivo para dirigir un respeto diferenciado hacia ellas.

Kant describe al respeto hacia una persona como "propiamente, solo respeto por la ley [...] de la cual la persona nos da el ejemplo. Ya que consideramos la expansión de nuestros talentos también como un deber, nos representamos a una persona con talentos también como un ejemplo de una ley [...]" (Kant, 1963a, p. 401, nota). Esto es elaborado en la Crítica de la razón práctica (Kant, 1963b, p. 7677), señalando que es un sentimiento irresistible por la ley moral ejemplificada en individuos virtuosos, y en La metafísica de la moral (Kant, 1968, p. 403, 410, 448-49; 462-73), donde precisa que este sentimiento genera deberes para con otras personas.
Asumir un respeto diferenciado por las personas que cultiven virtudes ambientales es asumirlo por personas que cotidianamente se relacionan con el ambiente en formas que no obstruyen la realización de los demás, altamente empáticas con los organismos no racionales o con entidades bellas en la naturaleza, y que evidencian una conciencia del deber por mantener un vínculo sostenible con el ambiente. Esto incluye a personas defensoras del medio ambiente, así como a las con-servacionistas de especies o localidades específicas; y también a personas de comunidades aborígenes que cultiven virtudes ambientales como parte de su imaginario cultural. Puede, asimismo, extenderse a personas que trabajen en modelos económicos alternativos y formas de producción más inocuas, y a personas que propongan y defiendan políticas para la adopción de principios éticos ambientales en la toma de decisiones desde los poderes públicos.

Con base en lo anterior, este respeto diferenciado implica que, reconociendo un ejemplo de moralidad en su relación con el medio ambiente y las demás entidades del mundo, se optará por proteger a las personas que exhiban la virtud ambiental, reconociendo su valor para nosotros y bus-cando promover la continuidad de sus vidas, junto con la replicación de sus prácticas e ideas. Este deber, como todo deber moral, conlleva que aun cuando tengamos algún interés contrapuesto al respeto por estos agentes, el interés deberá ceder ante el respeto, estando todos moralmente obli-gados - en un grado especial - a no obstruir a estos agentes en la obtención de sus fines relativos al medio ambiente. Por ende, el cuarto principio especial de la ética ambiental será:

- Principio especial de la ética ambiental (4): Promover y defender la virtud ambiental, tanto en uno mismo como en los demás.

\section{La dimensión jurídica de los deberes ambientales.}

Los deberes éticos que hemos justificado pueden entrar, por sí mismos, dentro del catálogo de la 
Doctrina de la Virtud en La metafísica de la moral. Ahora encaminaremos estas consideracio-nes hacia la producción de normativa coercible desde la autoridad, proponiendo una justificación de deberes ambientales con carácter jurídico, para ser insertas en la Doctrina del Derecho.

Esto puede lograrse agregando algunos factores diferenciantes. La transición es posible si -dado un contexto de sociedad civil- la autoridad política emprende la confección de normas que prescriban conductas concretas (pues los deberes jurídicos son perfectos) relativas al ambiente, por medio de un precepto coercitivo ${ }^{43}$. Los deberes éticos y los jurídicos, en mi lectura, comparten el mismo principio del imperativo categórico, radicando la diferencia en que los deberes jurídicos ver-san sobre el concurso de voluntades de la ciudadanía —es decir, son de fuente externa- mientras que los deberes éticos son de fuente interna (Kant, 1968, p. 224, 383) ${ }^{44}$.

La sociedad civil, en un supuesto contrato originario, delega su poder en cargos o instituciones que den estabilidad a la interacción dentro de ella ${ }^{45}$ y que legitimen la coerción real (y no solo intelectual) en caso de lesiones a los derechos de sus integrantes (Kant, 1978, p. 1,338) ${ }^{46}$. El acuerdo sobre esta coerción real es el incentivo externo para la obediencia de la ciudadanía a los estatutos legislativos emanados de la autoridad política, que versan sobre prescripciones, prohibiciones o permisos concretos y orientados hacia permitir "que la escogencia de cada uno coexista con la del otro de acuerdo con una ley universal de la libertad" (Kant, 1968, p. 230; 1969b, p. 21; 1969d, p. 292). A esto sigue que el que exista actividad interna del libre albedrío en toda decisión ejecutiva convierte a toda decisión en ética, pero aquellas relativos a la convivencia civil $-\mathrm{y}$, estrictamente,

43 Wood (1998, p. 192) también señala que Kant deja lugar para deberes jurídicos relativos a entidades no racionales.

44 Para una propuesta alternativa, cf. Willaschek (1997, p. 224).

45 Tomo esto como responsabilidad de la autoridad política, cf. Kant (1781, p. 316; 1787, p. 373).

46 Cf. Rivera Mendoza, (2017, p. 143-146). aquellas que pueden ser reguladas mediante una coerción legítima y real- serán jurídicos (Kant, 1978 , p. 1,337). Tomemos ahora los principios especiales de la ética ambiental, limitémoslos al concurso intersubjetivo de libertades, y expongamos los tres principios especiales del derecho am-biental resultantes:

- Principio especial del derecho ambiental (1):La protección jurídica de la libertad de otros seres humanos ejercitada a través de su ser animal (deberes de legislar y cumplir con leyes de protección de las condiciones ecosistémicas de las que depende la subsistencia de todo agente racional humano).

- Principio especial del derecho ambiental (2): La protección jurídica de la libertad de otros seres humanos ejercitada a través de su ser intelectual (deberes de legislar y cumplir con leyes orientadas a asegurar la equidad en la posibilidad de hacer un uso voluntario de los bienes ambientales).

- Principio especial del derecho ambiental (3): La protección jurídica y el fomento de la virtud ambiental (deberes de legislar y cumplir con leyes de acción afirmativa en favor de personas defensoras del medio ambiente, comunidades aborígenes y miembros de programas científicos, económicos o de otra clase orientados a un mejor uso de los recursos naturales).

Debe tenerse claro que está proscrita la intrusión de lo esencialmente ético en lo jurídico. Por ello, se entenderá que la juridicidad no tiene cabida en los deberes de uno para consigo mismo, por lo que no se puede incluir al perfeccionamiento moral propio como un bien jurídico que pueda ser protegido por la autoridad civil (al no tener relación con el principio del derecho, o sea, del concurso intersubjetivo de libertades $^{47}$ ). Ahora, distingamos entre dos

47 Cualquier intención ex auctoritas en este sentido cae en un paternalismo que, además de ser inútil, lesiona la auto-nomía ética y la dignidad de las personas (Kant, 1969c, p. 40, 1969d, p. 290-91). 
manifestaciones de los deberes ambientales jurídicos, dependiendo del carácter privado o público de los sujetos a los que obligan.

\subsection{El deber jurídico ambiental de los poderes estatales (dimensión pública).}

Con respecto a la autoridad en específico, esta tiene el deber jurídico de actualizar el siste-ma legal para que se aproxime, en la mayor medida, al derecho natural (Kant, 1969e, p. 372). Si se asume que los deberes ambientales aquí propuestos son válidos, y se acepta que algunos de ellos son jurídicos, puede concluirse que producir legislación ambiental coherente con el principio del imperativo categórico sería parte de deber jurídico perfecto de la autoridad. Ahora - si bien hemos dicho que el derecho a un medio ambiente sano se vincula con los derechos a la vida, la libertad personal y la integridad personal (junto con, p. ej. el derecho a la alimentación y a la salud) - la presente propuesta no admite que la protección a estos derechos pueda ser vista como un propósito legislativo en sí (por lo menos bajo esta óptica) sino como objeto de una protección derivada del deber ambiental por sí solo. Tampoco admite que esta protección legal se oriente hacia la promo-ción del bienestar de las generaciones actuales o las futuras, ni de la continuidad de la proliferación humana, sino como medida necesaria para asegurar que no se lesione la libertad de las personas o grupos que actualmente viven en el mundo ${ }^{48}$.

48 Esto difiere, por ejemplo, del deber para con generaciones futuras y pasadas que defiende Brown Weiss (1990, p. 202, 205). Si bien los tres principios de la «equidad intergeneracional» que Brown Weiss propone pueden servir para ilustrar los deberes ambientales que tenemos frente a los demás (en este momento), la presente lectura no admite pensar un deber para con entidades humanas aun no nacidas, pues estas no son objetos de la experiencia ni, en cualquier caso, podrían exhibir una racionalidad frente a nuestra facultad de juicio para tornarse en objetos de deber. Por otro lado, los deberes que aquí proponemos se sostendrían aun si hubiere una certeza de que la presente es la última generación humana, pues su validez no depende de una expectativa a futuro. El que Brown Weiss señale que los deberes no son para con individuos, sino generaciones de individuos, cae en la circularidad de que es imposible que un conglomerado - aun cuando todos sus miembros se manifestaran racionales - presen-te una voluntad unificada, por lo que debe
El carácter jurídico de los deberes ambientales nos habilita algunos mecanismos de control fuerte de la conducta ambiental, p. ej. será posible formular leyes positivas de carácter ambiental bajo la provisión de que estas contemplen acciones concretas con relativa especificidad (piénsese en una máxima ética, con sus circunstancias y objetos claramente consignados, junto con sanciones específicas y efectivas ante su infracción). Asimismo, las decisiones judiciales, como norma singularizada, también son receptivas a informarse de criterios morales ambientales, siendo especialmente útiles para direccionar un sistema de precedentes hacia una afirmación del espíritu protector del ambiente y de la condición diferenciada de algunas personas, p. ej.: «[...] es importante, además, señalar que la persona [...] es de especial importancia para la sociedad y para la humanidad, puesto que se dedicaba diariamente a la defensa del ambiente. Esto supone, para el Estado como para la sociedad en general, un deber de protección, respeto y fomento distinto que emanan desde la conducta ejemplar de [...]. Por ello, se acentúa la responsabilidad de [...] persona u organización que haya actuado en su perjuicio, el deber social de reparar cualquier daño y prevenir la comisión ulterior de hechos similares".

\subsection{El deber jurídico ambiental perfecto de la ciudadanía y la imposibilidad del conflicto de intereses en cuanto al ambiente (dimensión privada).}

La ciudadanía tiene el deber de cumplir con los estatutos producidos por la autoridad bajo el

haber tantos deberes (en sentido distributivo) como voluntades haya en el grupo, y por lo que no es posible deducir deberes sino frente a cada individuo. La única forma de ver a la humanidad como un grupo es abstrayendo de su carácter inteligible (y entonces del único asidero para pensar su liber-tad) y limitándonos a considerarla como una especie animal operando, en conjunto, bajo leyes de la naturaleza. Si bien esta operación es válida (p. ej. para el caso del estudio de la historia natural), la única manera de considerar a los deberes relativos a la especie homo sapiens, bajo este esquema, es como deberes indirectos (se la ve como a cualquier conglomerado de otros animales), a confrontarse - si se deseacon los deberes directos que se tienen frente a cada individuo visto como racional. 
supuesto del contrato originario ${ }^{49}$. Este postulado supone que una sociedad que se rija bajo el cumplimiento de las leyes producidas bajo la idea de un consentimiento común es una en la que cada quien respeta la libertad de los demás y la suya propia ${ }^{50}$. Según esta idea, cada persona se encuentra desautorizada para negligir los estatutos legales, aun si considera que estos son antijurídicos, pero tiene también el deber jurídico perfecto —dado un sistema de designación plebiscitaria de la autoridad legislativa - de velar por la remoción de los agentes públicos que no defiendan al medio ambiente y por la promoción de aquellos agentes que lo hagan.

Ahora, el principio jurídico del concurso de libertades no es igual a la idea usual de que "el derecho de una persona se encuentra limitado por el derecho de otra", cuando no se entiende que el propósito del principio jurídico no es la protección de todos los intereses de toda persona frente a las demás - en una suerte de colisión multidireccional y constante - sino mitigar la coerción privada y el acercamiento a la paz entre individuos, instituciones y Estados (Kant, 1973, p. 333). La protección jurídica del ambiente, en consecuencia, no equivale a la protección de aquello que cada quien piense o desee con respecto al ambiente frente a otros ciudadanos, sino el aseguramiento del ejer-cicio mismo de las libertades en concurso (entendido que la lesión al medio ambiente es una lesión a uno mismo y a toda otra persona). Por ende, no puede coherentemente esgrimirse el argumento jurídico de que una persona se encuentra en derecho de hacer cuanto pueda por proteger al medio ambiente cuando otra puede actuar legítimamente en contrario. La diferencia radica en que esta última, bajo un argumento de esa clase, pretende lesionar la libertad del resto de las personas en el mundo, mientras que la primera pretende protegerla. Por ello, toda persona que invoque un interés jurídico legítimo con respecto a los bienes ambientales necesariamente invocará su protección.

49 Cf. Kant (1969d, p. 298).

$50 \mathrm{El}$ planteamiento kantiano, en este sentido, es similar al de Rousseau (1796, p. 43).

\section{CONCLUSIóN. Hacia una nueva legislación ambiental principiada.}

Desde lo anterior, frente al medio ambiente, nuestra idea debe ser que "el objeto del dere-cho ambiental de una persona es idéntico al objeto del derecho ambiental de toda otra persona". Lo vulnerable de la corporeidad humana es un ecualizador de la condición de toda persona: si el ambiente se degrada hasta cierto punto, no habrá individuo - por muy en posesión de recursos de cualquier clase en que pudiera encontrarse- que logre eludir el daño a su cuerpo y, consecuentemente, a su libertad. El máximo interés del derecho ambiental debe ser el de promover la convivencia armoniosa entre el ser humano y el resto del entorno, no la convivencia armoniosa entre cualquier interés humano que olvide nuestra ineludible vulnerabilidad ante los cambios en el medio ambiente.

La actual catástrofe ambiental, que bien puede que próximamente conduzca al fin de múlti-ples formas de vida, no justifica que dejemos de intentar lograr conductas más correctas, sin impor-tar cómo llegue a concluir nuestra existencia. Desde el punto de vista del derecho, puede recordarse por ahora- que detrás de la producción legislativa debe existir una deliberación suficiente para determinar si la norma bajo la que se pretende que la ciudadanía se conduzca es verdaderamente jurídica $y$, entonces, si exhibe resiliencia frente a las propuestas y cuestionamientos del dogmatismo y el escepticismo. Si la perspectiva deóntica aquí solamente esbozada llegare a probarse sostenible, puede avizorarse un derecho ambiental completo y con fundamento racional, vinculado con el resto de la ciencia, y que haya superado la inestabilidad y propensión a la obsolescencia de todo intento legal contingente y reactivo. 


\section{BIBLIOGRAFÍA}

- Allison, H. (2004), Kant's Transcendental Idealism: An Interpretation and Defense (revised. and enlarged edition), Yale University Press: New Haven \& London.

- Allison, H. (2011), Kant's Groundwork for the Metaphysics of Morals: A Commentary, Oxford: Oxford University Press.

- Brown Weiss, E. (1990), "Our Rights and Obligations to Future Generations for the Environ-ment", The American Journal of International Law 84 (1), 198.

- Bruinsma, J. (2009) The Resource Outlook to 2050: By How Much do Land, Water and Crop Yields need to increase by 2050?, ensayo presentado en la cumbre de expertos de la FAO "How to Feed the World in 2050", 24-26 de junio de 2009, Roma.

- D'Amato A. y Eberle, E.J. (1983) "Three Models of Legal Ethics", 27 Saint Louis University Law Journal, 761.

- Kant, I. (1781), Critik der reinen Vernunft (primera edición), Riga: Hartknoch.

- Kant, I. (1787), Critik der reinen Vernunft (segunda edición), Riga: Hartknoch.

- Kant, I. (1963a), "Grundlegungzur metaphysik der Sitten", Akademieausgabe von Immanuel Kants Gesammelten Werken, Vol. 4:387, Berlín: de Gruyter, orig. 1785.

- Kant, I. (1963b), "Kritik der praktischen Vernunft", Akademieausgabe von Immanuel Kants Gesammelten Werken, Vol. 5:3, Berlín: de Gruyter, orig. 1788.

- Kant, I. (1963c), "Kritik der Urteilskraft", Akademieausgabe von Immanuel Kants Gesammelten Werken, Vol. 5:167, Berlín: de Gruyter, orig. 1790.
- Kant, I. (1968), "Die Metaphysik der Sitten", Akademieausgabe von Immanuel Kants Gesammelten Werken, Vol. 6:203, Berlín: de Gruyter, orig. 1797-1798.

- Kant, I. (1969a) "Die Religion innerhalb der Grenzen der blossen Vernunft", Akademieausgabe von Immanuel Kants Gesammelten Werken, Vol. 6:3, Berlín: de Gruyter, orig. 1793.

- Kant, I. (1969b) "Idee zu einer allgemeinen Geschichte in weltburgerlicher Absicht", en Akade-mieausgabe von Immanuel Kants Gesammelten Werken, Vol. 8:17, Berlín: de Gruyter, orig. 1784.

- Kant, I. (1969c), "Beantwortung der Frage: Was ist Aufklärung?", Akademieausgabe von Immanuel Kants Gesammelten Werken, Vol. 8:35, Berlín: de Gruyter, orig. 1784.

- Kant, I. (1969d) “Über der Gemeinspruch: Das mag in der Theorie richtig sein, taugt aber nicht für die Praxis", Akademieausgabe von Immanuel Kants Gesammelten Werken, Vol. 8:275, Ber-lín: de Gruyter, orig. 1793.

- Kant, I. (1969e) "Zum ewigen Frieden. Ein philosophischer Entwurf", Akademieausgabe von Immanuel Kants Gesammelten Werken, Vol. 8:343, Berlín: de Gruyter, orig. 1795.

- Kant, I. (1971) "Erste Einleitung in die Kritik der Urteilskraft" en Akademieausgabe von Imman-uel Kants Gesammelten Werken, Vol. 20:193, Berlín: de Gruyter.

- Kant, Immanuel (1973). "Anthropologie in pragmatischer Hinsicht", en Akademieausgabe von Immanuel Kants Gesammelten Werken, Vol. 7:119, Berlín: de Gruyter, orig. 1798.

- Kant, I. (1978) "Naturrecht Feyerabend", en Akademieausgabe von Immanuel Kants Gesammelten Werken, Vol. 27:1,319, Berlín: de Gruyter, orig. cátedra de 1784. 
- Mgbemene, Chigbo A.; Nnaji, Chidozie C.; Nwozor, Chekwubechukwu (2016), "Industrialization and its Backlash: Focus on Climate Change and its Consequences", Journal of Environmental Science and Technology, 9, 301-316.

- Zalasiewicz, J., Williams, M., Smith, A., Barry, T. L., Coe, A. L., Bown, P. R., ... Stone, P. (2008). "Are we now living in the Anthropocene?" GSA Today, 18(2), 4-8.

- Rivera Mendoza, L. (2017), “El matrimonio igualitario: el caso de Honduras y una perspectiva kantiana" Revista IIDH 66, 6, 143-146.

- Rousseau, J.J. (1796), Du contrat social, ou principes du droit politique, Leipzig: Gerard Fleis-cher, orig. 1762.

- Walker, R. J. (2016). "Population Growth and its Implications for Global Security", The American Journal of Economics and Sociology $75,4$.

- Willaschek, M. (1997). "Why the Doctrine of Right does not belong in the Metaphysics of Mor-als: On some Basic Distinctions in Kant's Moral Philosophy", Annual Review of Law and Ethics 5, 205-227.

- Wood, A. (1998), "Kant on Duties Regarding Nonrational Nature", The Aristotelian Society, supl. vol. 72, 189-228.

- Wood, A. (2000). “The Final Form of Kant's Practical Philosophy," Mark Timmons (ed.) Essays on Kant's Moral Philosophy. New York: Cambridge University Press. 